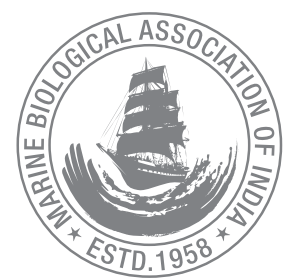

\title{
Good Environment Management of cage farming using a coupled 3D hydrodynamic particle tracking model - A case study from Pizhala, Cochin, India
}

\author{
Sebin John ${ }^{1,2}$, K. R. Muraleedharan ${ }^{1 *}$, C. Revichandran', Vineetha Valsalan ${ }^{3,4}$, V. Kripa ${ }^{3}$, \\ S. Abdul Azeez', G. Seena ${ }^{1,2}$ and Ravi Kumar C. Nair \\ ${ }^{1}$ CSIR-National Institute of Oceanography, Regional Centre, Kochi- 682 018, Kerala, India. \\ ${ }^{2}$ Bharathidasan University, Tiruchirappalli, Tamil Nadu-620 024, India. \\ ${ }^{3}$ ICAR-Central Marine Fisheries Research Institute, Kochi-682 018, Kerala, India. \\ ${ }^{4}$ Cochin University of Science and Technology, Lakeside Campus, Kochi- 682022. \\ *Correspondence e-mail: muraleedharan@nio.org
}

Received: 20 March 2020 Accepted: 25 July 2020 Published: 30 July 2020

Original Article

\begin{abstract}
Hydrographic conditions such as water level, velocity, adequate water circulation and stratifications have a strong influence on the management of fish cage culture in the estuarine environment. In this study, a 3D hydrodynamic model was used to identify the areas of the mixed and stratified water column and to use this in conjunction with particle tracking models for appropriate site selection for cage culture. A Lagrangian method was used to simulate the instantaneous release of "particles" emulating discharge from fish cages to show the behaviour of waste in terms of water circulation and water exchange. Model simulation at Pizhala cage farm revealed that desirable water exchange is experienced in the monsoon and pre-monsoon period. There have existed strong spring-neap variability in the water level with an average range of $0.7 \mathrm{~m}$ with a speed of $<0.12 \mathrm{~m} / \mathrm{s}$ in pre-monsoon and $<0.24 \mathrm{~m} / \mathrm{s}$ in monsoon. This consistent flow patterns in the Pizhala region helps in the replenishment of oxygenated water and removal of waste produced beneath the cages, and it is corroborated by the Lagrangian particle transport model experiment coupled with Finite Volume Community Ocean Model (FVCOM) in the study.
\end{abstract}

Keywords: Cochin Estuary, hydrodynamics, modelling, aquaculture

\section{Introduction}

Aquaculture is one among the world's most significant animal food production, and the momentous intensification of aquaculture production was prominent over the last few decades due to the increasing worldwide demand for fish protein. However, inadequate use of aquaculture fields adversely affects natural systems which are a growing cause of environmental concern (Holmer, 2010). Sustainability of aquaculture depends on many factors, including environmental and ecological interactions, production strategies, and management decisions as well as social and economic concerns. By 2030, India needs to produce 18 million tonnes of fish compared to the present 10 million tonnes (Department of Animal Husbandry Dairying \& Fisheries, 2018). In this stride, the biggest constraint in aquaculture is the need for the constant flow of pure water which ensures sufficient supply of oxygen and other nutrients required by the farmed organism. Cage farming as improved technology for fish culture in India was first experimentally demonstrated by the Central Marine Fisheries Research Institute (CMFRI) in 2007 in Visakhapatnam using a $15 \mathrm{~m}$ diameter cage. Several species of fish like milkfish, mullet, cobia, pompano, seabass, pearl spot etc. are considered as candidate species for cage farming in India. Though the cage farms were established to utilise the natural water bodies that provide suitable conditions for the 
growth of fish, the environmental impact of waste discharges from the same is reckoned on their nature and magnitude along with prevailing physical, chemical and ecological conditions of the ambient waters to make a suitable modification.

There are several factors need to be considered in determining the optimised position of the cage in open water, including environmental, infrastructural components (Ross et al., 2013; 2011) and visual impacts (Falconer et al., 2013). It is essential to define the ideal area for cage farming, since each cage has engineering tolerances in a different physical environment, with varying degrees of climate and a specific range of hydrographic conditions. The massive deployment of the cages in an area without considering the carrying capacity and compatibility may alter the Physico-chemical and biological conditions like density, species richness, and overall abundances of benthic organisms ( Machias et al., 2004; Edgar et al., 2010; Riera et al., 2013). Moreover, site selection has a substantial role in the economic viability by estimating the capital expenditure, running cost, rate of production and mortality.

Over the past 20 years, modelling of sea cage aquaculture using different techniques such as GIS, remote sensing, hydrographic and hydrodynamic models coupled with biological aspects has been used for broader research and societal applications (Gowen et al., 1989; Findlay and Watling, 1994; Hevia et al., 1996; Cromey et al., 2002; Perez et al., 2002; Stigebrandt et al., 2004; Assefa et al., 2018; Estigade et al.,2019) including prediction of the impact of cage culture in coastal waters and to support the regulatory authorities to impound license for new cage farms and permissions for the effluent discharges. Though, these models are costeffective tools but are still less prevalent due to the accuracy and precision required to calibrate and validate the model depending on variables such as oceanographic conditions or culture features. In the present study, FVCOM 3D model coupled with Lagrangian particle tracking module used to elucidate the flushing efficiency and residual circulation of cage farms at Pizhala, Vembanad Lake. After the validation, the model results were utilised to bring out the Spatiotemporal patterns of average current speed, tidal elevation, quiescent water periods, stratification, circulations and renewal time, to determine interrelationships between the tide and freshwater flows on the residual circulation.

\section{Material and methods}

\section{Outline}

A validated hydrodynamic model for the Vembanad lake was adopted in this study at Pizhala and simulated the hydrodynamic properties (tidal currents, currents, salinity. etc) and particle motion to analyse its ability to remove waste particles from the cages. Modelling results were then compared with the sediment characteristics of the study area and identified possible mechanisms for the seasonal difference in organic content in the sediment.

\section{Study Area}

Vembanad Lake (VL): VL is the second-largest wetland ecosystem in India, encompassing an area of approximately $260 \mathrm{~km}^{2}$ (Fig.1), interspaced with numerous islands and networks of canals making the circulation and transport mechanism very complex (Revichandran et al., 2012) its propagation in the backwater system is very complicated, particularly in the northern arm of the estuary. Using synchronous water level (WL) VL has aligned parallel to the Arabian Sea over $96 \mathrm{~km}$ from Munambam to Alappuzha, and it directly connected to the Arabian Sea through Cochin ( $450 \mathrm{~m}$ wide, depth $>15 \mathrm{~m}$ ) and Munambam ( $250 \mathrm{~m}$ wide, depth $>7 \mathrm{~m}$ ). The tide in the VL has mixed semidiurnal nature with a range of $1 \mathrm{~m}$ that progressively decreases towards upstream (Srinivas et al., 2003; Revichandran et al., 2012; Vinita et al., 2015). The Kochi Backwater (KB) receives a high supply of freshwater $\left(22000 \mathrm{Mm}^{3} / \mathrm{year}\right.$ ) annually from seven rivers flowing from the Western Ghats with peak discharge in the summer monsoon. During the monsoon period, VL becomes a freshwater dominated system except in the inlet regions, while in the post-monsoon season, the river discharges become moderate; as a result, tidal energy propagates to the upstream, thereby changing the freshwater conditions to partially mixed type. In pre-monsoon season, minimum river discharge and maximum seawater incursion to the upstream leave the VL well mixed, and homogeneity exists in the water column up to Thanneermukkom Barrage (Menon et al., 2000).

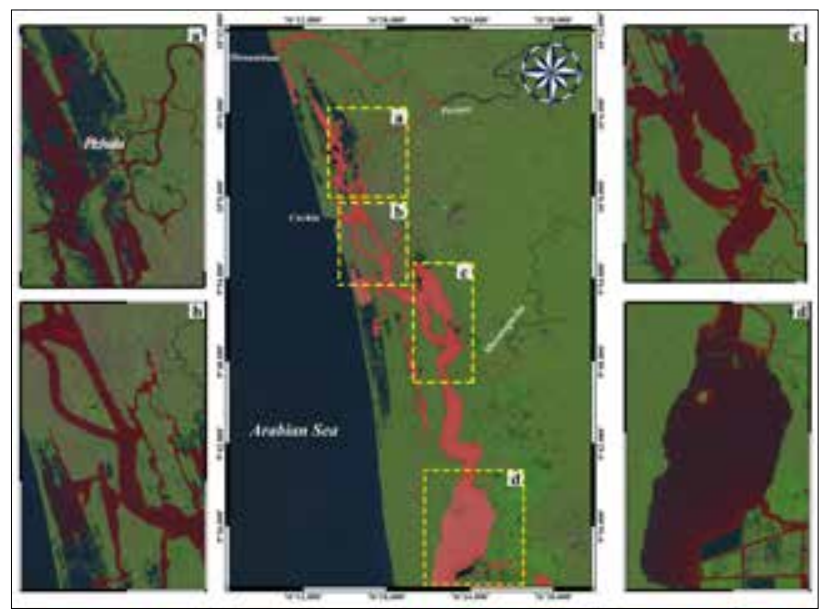

Fig. 1. Landsat 8 image of the model domain and a, b, c \& d illustrate the fine resolution of boundary fitter unstructured grid for the various geometries (Islands and meandering boundaries) of the VL 
Pizhala Island: The successful demonstration of cage cultivation by ICAR-CMFRI in the coastal waters in 2009 has led to the widespread adoption of the technique by Pizhala (Fig. 2), a tiny island village in Kerala's scenic backwater VL (Imelda and Gopalakrishnan, 2017; Aswathy and Imelda, 2018). The dominant species cultivated in Pizhala are Asian seabass (Lates calcarifer), Pearlspot (Etroplus suratensis), Tilapia (Oreochromis sp.) and Mullet (Mugil sp.). Presently, around 100 farming units are ongoing near to Pizhala Island under the guidance of CMFRI, where most of the farmers are women. The geographical settings of the region include high freshwater flow from the river Periyar features narrow width and shallow depths $(<5 \mathrm{~m})$.

\section{In-situ observations}

Tide measurements: Seasonal understanding of the hydrodynamics of $\mathrm{VL}$ is essential to set up a hydrodynamic model. One month long, time-series observations of tides
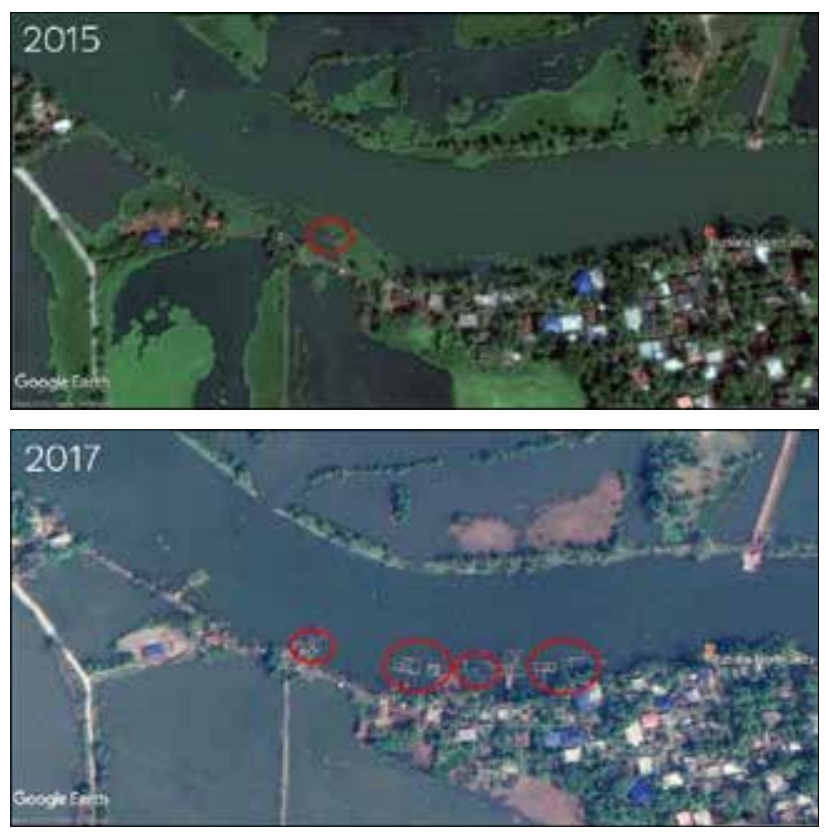

Fig. 2a. Satellite images of cage culture (red circle) at Pizhala during the year of 2015 and 2017.

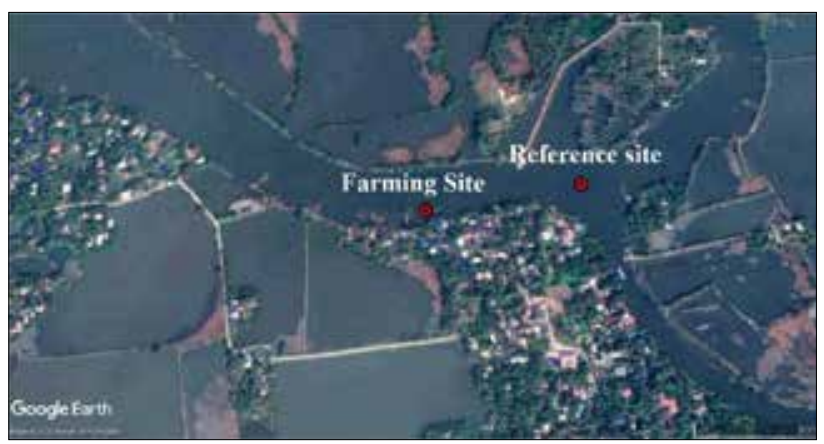

Fig. 2b. Locations for the sediment sample from the farming and reference sites are marked with red circle dots.
(SBE 26plus Tide Recorder- 10 minutes interval) were carried out under the low (22-2-2010 00:00 hrs to 22-3-2010 08:00hrs) and high (24-07-2010 00:00hrs to 21-08-2010 00:00hrs) runoff conditions during the year of 2010 at 7 locations (Fig. 3). Stations 2-3 are along the northern arm and stations 8-10 are along the southern arm. Station 1\&7 represents Munambam/Azhikode inlet and Fort Kochi inlet, respectively.

Velocity measurements: Time-series measurements of currents were conducted both during low (22-2-2010 00:00hrs to 22-3-2010 08:00hrs) and high (24-07-2010 00:00hrs to 21-08-2010 00:00hrs) discharge periods at four locations (Fig. 3). Aanderaa RCM-9 current meters were used to record speed and direction with an accuracy of $\pm 0.15 \mathrm{cms}$

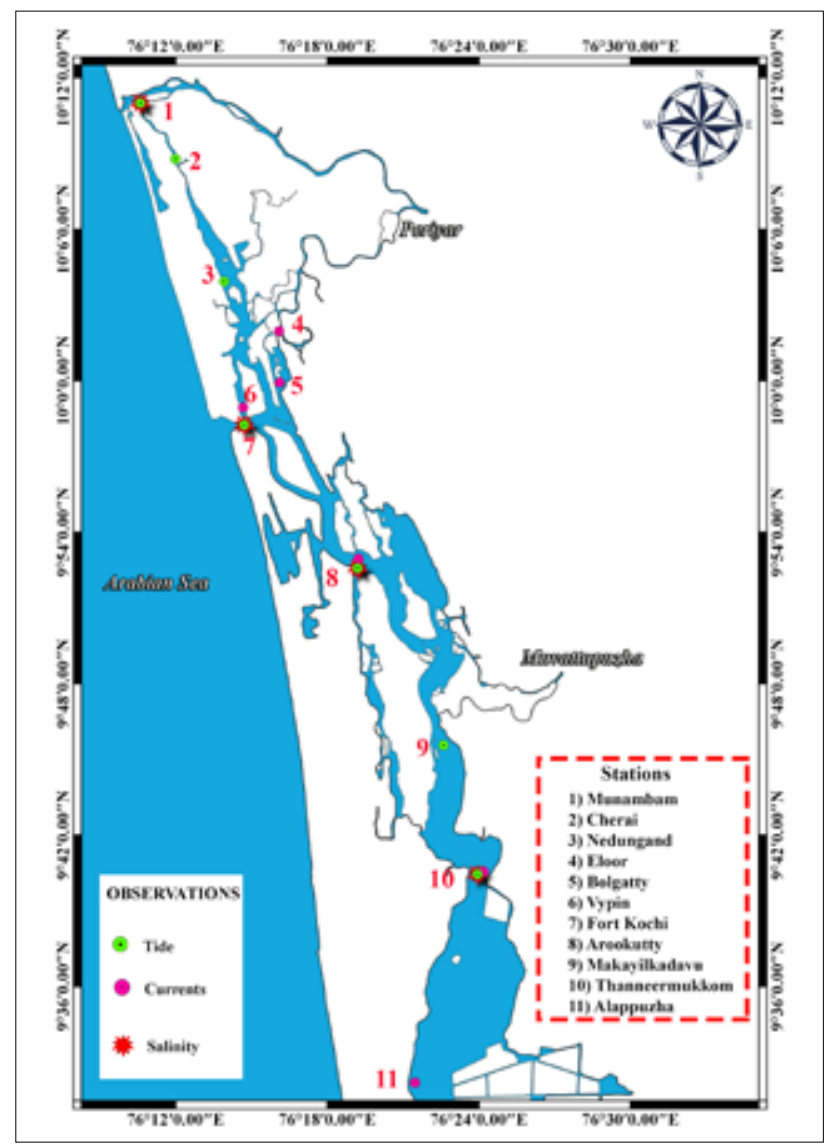

Fig. 3. Tides, Currents, and salinity measurements at various locations at VL.

$1 ; \pm 2^{0}$ is used for the observations at all stations $(1,7,8$, and $10)$ at 10-minute intervals.

Salinity measurements: Daily salinity measurement at Vypin $(10: 30 \mathrm{am})$ and Bolgatty $(11: 30 \mathrm{am})$ were carried out using SBE 19 plus CTD between 1-06-2013 to 31-052014 (Fig. 3). Water samples were collected from four locations simultaneously at 11:00 am daily (Eloor, Arookutty, Thanneermukkom, and Alappuzha) between 1-01-2014 to 
31-12-2014 by involving public participation, and theses samples were analysed in the laboratory using Eutech salinity probe.

Sediment Characteristics of Cages at Pizhala: Excessive waste disposal in cage farm area can alter sediment characteristics, and the most common physical changes in sediment are observed in the particle size composition (texture). Henceforth a fine, flocculent layer or organic material will overlay the natural substrate (Winsby et al., 1996) and its thickness is different depending on sedimentation rate and the horizontal transportation of particles. This leads to the build-up of organic matter in the bottom sediment with the resultant depletion of oxygen and alteration of benthic communities. For understanding the seasonal characteristics, sediment samples were collected using van-Veen Grab $\left(0.05 \mathrm{~m}^{2}\right.$ area) from two locations in the cage culture sites of Pizhala island during pre-monsoon (2016) and monsoon seasons (2017). Of these, one is selected nearer to the cages $(\sim 3 \mathrm{~m})$ and the other one taken $300 \mathrm{~m}$ apart from the cages towards the riverine side (reference station). The sediment organic carbon was analysed using wet oxidation method (El Wakeel and Riley, 1957) and sediment texture was analysed using Krumbein and Pettijohn (1938) method.

\section{Finite Volume Community Ocean Model settings of Vembanad Lake (VL-FVCOM)}

FVCOM is a finite-volume, free-surface, 3-D primitive equation which was developed by UMASSD-WHOI. The unstructured-grid facility in this model performs for the complex estuarine/coastal and ocean processes (Chen et al., 2003). The model consists of momentum, continuity, temperature, salinity and density equations and is closed physically and mathematically using turbulence closure sub models. The horizontal grid is comprised of unstructured triangular cells and the irregular bottom is presented using sgeneralised terrain-following coordinates. FVCOM is solved numerically by a second-order accurate discrete flux calculation in the integral form of the governing equations over an unstructured triangular grid. This approach combines the best features of finite-element methods (grid flexibility) and finite-difference methods (numerical efficiency and code simplicity) and provides a much better numerical representation of both local and global momentum, mass, salt, heat, and tracer conservation.

Momentum:

$$
\begin{gathered}
\frac{\partial u}{\partial t}+u \frac{\partial u}{\partial x}+v \frac{\partial u}{\partial y}+w \frac{\partial u}{\partial z}-f v=-\frac{1}{\rho_{0}} \frac{\partial p}{\partial x}+\frac{\partial}{\partial z}\left(k_{m} \frac{\partial u}{\partial z}\right)+F_{u} \\
\frac{\partial v}{\partial t}+u \frac{\partial v}{\partial x}+v \frac{\partial v}{\partial y}+w \frac{\partial v}{\partial z}+f u=-\frac{1}{\rho_{0}} \frac{\partial p}{\partial y}+\frac{\partial}{\partial z}\left(k_{m} \frac{\partial v}{\partial z}\right)+F_{v} \\
\frac{\partial p}{\partial z}=-\rho g
\end{gathered}
$$

Continuity:

$$
\frac{\partial u}{\partial x}+\frac{\partial v}{\partial y}+\frac{\partial w}{\partial z}=0
$$

Temperature:

$$
\frac{\partial T}{\partial t}+u \frac{\partial T}{\partial x}+v \frac{\partial T}{\partial y}+w \frac{\partial T}{\partial z}=\frac{\partial}{\partial z}\left(k_{h} \frac{\partial T}{\partial z}\right)+F_{T}
$$

Salinity:

$$
\frac{\partial S}{\partial t}+u \frac{\partial S}{\partial x}+v \frac{\partial S}{\partial y}+w \frac{\partial S}{\partial z}=\frac{\partial}{\partial z}\left(k_{h} \frac{\partial S}{\partial z}\right)+F_{S}
$$

Density:

$$
\rho=\rho(T, S)
$$

Where $x, y, z$ are the Cartesian coordinates; $u, v, w$ are the velocity components; $f$ is the Coriolis parameter, $P$ is the pressure, $\mathrm{Km}$ is the vertical eddy viscosity term, $\mathrm{F}$ is the horizontal eddy viscosity term, $\rho$ is the density, $\rho 0$ is the reference density and $\mathrm{g}$ is the gravitational acceleration.

For the present study, the triangular grid for VL- FVCOM was generated using GMSH software and it consists of 15479 nodes with 22520 elements (Table 1) where bathymetry data obtained from IWAI chart-2006 has been interpolated to nodes (Fig. 1). The model was forced with the tide from two open boundaries (Munambam and Fort Kochi). For this surface water elevations at each hour were calculated at the two open ocean boundaries using the 25 tidal constituents. These tidal constituents are derived from the one-year tide data at Munambam and Fort Kochi using Tidal Analysing Software Kit 2000 developed at Proudman Oceanographic Laboratory in the United Kingdom. The daily river discharge data from the gauging stations were obtained from the Central Water Commission (CWC), Government of India. FVCOM Model simulations were performed from 2009 to 2015 for validating with available seasonal hydrographic datasets. The correlation coefficient $\left(\mathrm{R}^{2}\right)$ and Index of Agreement (d) (Willmott, 1981) used to evaluate the model performance over the measured values of water level, velocity and salinity at various locations in the $\mathrm{VL}$

The model simulations were carried out from 2009 to 2017 and then compared model outputs with available in-situ observations (John et al., 2020). The model simulations also covered both pre-monsoon and monsoon conditions, which were relevant to the present study. Two statistical parameters namely, correlation (R) and index of agreement parameter (d) were used to compare the model results with observations. Finally, the flushing characteristics of Pizhala was studied by releasing 1000 passive tracer particles emulating discharge at fish cage farm during a period of tidal cycle (2 flood-ebb) in 
Table 1. Parameters used in the model simulations

\begin{tabular}{ll}
\hline Physical Parameter & Numerical Value \\
\hline Time-step & $1 \mathrm{~s}$ \\
\hline Grid mesh & $10-600 \mathrm{~m}$ \\
\hline Nodes & 15479 \\
\hline Elements & 22520 \\
\hline Vertical coordinate & 10 -unifrom sigma layers \\
\hline Drag coefficient & 0.03 \\
\hline River discharge & Observed \\
\hline Temperature & Climatological \\
\hline Salinity & Climatological \\
\hline
\end{tabular}

pre-monsoon (2016) and monsoon (2017). Modelling results were then compared with the sediment characteristics of Pizhala and identified possible mechanisms for seasonal difference in organic content in the sediment.

where $P$ and $O$ represents model predicted and observed values respectively, is time mean of $O$, and $N$ is the size of the data set. Perfect agreement between model results and observations yields a skill value of one and complete disagreement gives a skill value of zero.

\section{Numerical Approach for cage culture suitability}

A detailed investigation of hydrographic features of Pizhala was simulated using a calibrated and validated VL-FVCOM 3D model. Model simulations performed for pre-monsoon (January-March, 2016) and monsoon (June-August, 2017) according to the river discharge. An advanced management tool for this type of particulate wastes is its dynamic simulation utilising Lagrangian particle-tracking models (Cromey et al., 2002; Cromey and Black, 2005). In the present study, the Finite Volume Community Ocean Model (FVCOM) coupled with the Lagrangian particle module was used to estimate the behaviour of the waste discharge from the fish cages at Pizhala in terms of water circulation and water exchange (Table 2). The flushing characteristics of the area was studied by releasing 1000 passive

Table 2. Hydrodynamic suitability conditions for fish cage farm

\begin{tabular}{ll}
\hline Physical Parameter & Suitability conditions \\
\hline Depth $(\mathrm{m})$ & $3-20$ \\
\hline Tidal range $(\mathrm{m})$ & $<2 \mathrm{~m}$ \\
\hline Velocity $(\mathrm{m} / \mathrm{s})$ & $>0.03$ \\
\hline Salinity $(\mathrm{psu})$ & $0-20$ \\
\hline Temperature $\left({ }^{\circ} \mathrm{c}\right)$ & $26-30$ \\
\hline Flushing time $($ days $)$ & $1-3$ \\
\hline River point $(\mathrm{km})$ & $2-5$ \\
\hline Human Settlement & Moderate
\end{tabular}

tracer particles emulating discharge at fish cage farm (sigma layer $=10$ ) during a period of tidal cycle (2 flood-ebb) in premonsoon (2016) and monsoon (2017).

\section{Results and discussion}

\section{Validation of the VL-FVCOM model}

Tides: The model performance was evaluated qualitatively using an agreement of index and correlation. The surface water elevation at all stations captured very well with an average agreement of index of 0.96 and a correlation coefficient of 0.92 (Table 3). Among these locations, Stn.1 (Munambam) and Stn.7 (Fortkochi) have the best fit to the observed value with an agreement of index and correlation coefficient of 0.99 . Most of the stations exhibited $\geq 90 \%$ of correlation during pre-monsoon and monsoon except at Thanneermukkom (station 10), where the index of agreement was 0.86 , and the correlation coefficient was 0.75 .

Currents: The tidal signals dominated currents in the VL and the model was able to capture the diurnal inequality and spring-neap variability. Comparison between the model and observed velocities (east-u and north-v component) at 4 stations showed a good agreement of index for the predicted velocities with an average of 0.80 and a correlation of 0.78 (Table 4) during the pre-monsoon and monsoon. Bi-directional flow noticed at Fort Kochi inlet during the flood period (surface layer flow towards the sea while bottom layer to the lake) had been captured by the model vividly, where the index of agreement with the observed data at surface and bottom was 0.81 and 0.76 respectively. The majority of the stations exhibit $\geq 70 \%$ of the correlation in velocity during pre-monsoon and monsoon expect at Thanneermukkom. The low correlation observed in the Thanneermukkom region was 0.8 in an index of agreement and 0.83 in the correlation coefficient for the axial component of the velocity.

Salinity: During the simulation period, the FVCOM model was able to deliver the seasonal variation of the surface salinity pattern with respect to the freshwater influx. The

Table 3. The index and correlation values of the predicted/simulated tides at seven locations in CE during pre-monsoon (2010) and monsoon (2010).

\begin{tabular}{lllll}
\hline \multirow{2}{*}{ Stations } & \multicolumn{2}{c}{ Index of agreement } & \multicolumn{2}{c}{ Correlation coefficient } \\
\cline { 2 - 5 } & Pre-monsoon & Monsoon & Pre-monsoon & Monsoon \\
\hline Stn.1 & 0.99 & 0.99 & 0.99 & 0.99 \\
\hline Stn.2 & $* *$ & 0.95 & $* *$ & 0.98 \\
\hline Stn.3 & 0.94 & $* *$ & 0.94 & $* *$ \\
\hline Stn.7 & 0.98 & 0.99 & 0.97 & 0.99 \\
\hline Stn.8 & 0.95 & 0.98 & 0.93 & 0.97 \\
\hline Stn.9 & 0.96 & 0.91 & 0.94 & 0.85 \\
\hline Stn.10 & $* *$ & 0.86 & $* *$ & 0.75 \\
\hline
\end{tabular}

** No Measurements 
large longitudinal salinity gradients range from 0 psu (Stn.4, Stn.8, Stn.10 and Stn.11) to 35 psu (Stn.5 and Stn.6) was observed in high river discharge periods, and the maximum saline intrusion (13 psu) was observed at southern upstream (Stn.10) of VL in low river discharge period. Six locations at VL showed (Table 5) an average value of correlation is 0.87 and the index of the agreement is 0.9 during 2013-2014. The majority of the stations showed similarity to the observed salinity in the agreement of index and correlation.

Hydrodynamics at Pizhala cage culture: A detailed understanding of the hydrodynamics of water

Table 4. The index and correlation value for the model and correlations of the time series currents ( $U$ and $V$ Components) at four locations in VL during pre-monsoon (2010) and monsoon (2010).

\begin{tabular}{|c|c|c|c|c|c|}
\hline \multirow{2}{*}{ Stations } & \multirow[t]{2}{*}{$\begin{array}{l}\text { Velocity } \\
\text { Components }\end{array}$} & \multicolumn{2}{|c|}{ Index of agreement } & \multicolumn{2}{|c|}{ Correlation coefficient } \\
\hline & & Pre-monsoon & Monsoon & Pre-monsoon & Monsoon \\
\hline \multirow{2}{*}{ Stn.1 } & U & 0.93 & 0.71 & 0.92 & 0.62 \\
\hline & V & 0.84 & 0.81 & 0.92 & 0.64 \\
\hline \multirow{2}{*}{ Stn.7 (Surface) } & U & 0.76 & 0.87 & 0.74 & 0.77 \\
\hline & V & 0.69 & 0.70 & 0.67 & 0.69 \\
\hline \multirow{2}{*}{ Stn.7 (Bottom) } & $U$ & 0.81 & ** & 0.80 & ** \\
\hline & V & 0.76 & $\star *$ & 0.72 & ** \\
\hline \multirow{2}{*}{ Stn. 8} & $U$ & ** & 0.95 & ** & 0.90 \\
\hline & V & ** & 0.94 & ** & 0.91 \\
\hline \multirow{2}{*}{ Stn.9 } & U & 0.61 & 0.80 & 0.62 & 0.87 \\
\hline & V & 0.60 & 0.86 & 0.61 & 0.91 \\
\hline
\end{tabular}

** $=$ No Measurements

parcel at cage farms is highly essential to make a better impact on the economics of the sustaining of fish production. Reasonable water exchange is required for the replenishment of oxygenated water and the removal of waste metabolites in the cage. A strong tidal interaction was observed at Pizhala with a tidal range of $0.7 \mathrm{~m}$ and $0.82 \mathrm{~m}$ in pre-monsoon and monsoon respectively (Fig. $4 \mathrm{a}$ and $6 \mathrm{a}$ ). Vertical variation of the tidal speed was minimum, and the speed of less than $0.12 \mathrm{~m} / \mathrm{s}$ was observed in the pre-monsoon and $0.23 \mathrm{~m} / \mathrm{s}$ in monsoon period with a consistent flow at surface and bottom (Fig. $4 \mathrm{~b}$ and $6 \mathrm{~b}$ ). It is worth to mention that a weak and continuous currents stream at Pizhala is favourable

Table 5. The index and correlation value and correlations of the predicted/simulated daily surface salinity at six locations in VL during 2013-2014.

\begin{tabular}{lll}
\hline Stations & Index of agreement & Correlation coefficient \\
\hline Stn.4 & 0.70 & 0.53 \\
\hline Stn.5 & 0.94 & 0.88 \\
\hline Stn.6 & 0.94 & 0.91 \\
\hline Stn.8 & 0.96 & 0.98 \\
\hline Stn.10 & 0.98 & 0.98 \\
\hline Stn.11 & 0.88 & 0.96 \\
\hline
\end{tabular}

to fetching of oxygenated water and removal of bottom waste materials at the cage. The maximum tidal range and the current streams were obtained in the spring period than the neap. Also, a shift in the magnitude of average currents were observed in the monsoon due to the steady influx from the Periyar river. The river influx of the Periyar gets transported through other tributaries and channels of the $V L$, hence the chances of the exceeding velocity from $1 \mathrm{~m} / \mathrm{s}$ at Pizhala are rather remote except at catastrophic events. Rapidly fluctuating conditions of temperature and salinities are harmful to marine life culture. The maximum saline intrusion was predicted in the pre-monsoon than the monsoon with a stratified water column (Figs. 5 and 7). The seasonal fluctuation in salinity was observed with a maximum salinity at pre-monsoon (16 psu-surface and 22 psu-bottom) and minimum at monsoon (0 psu-surface and 6 psu-bottom). These considerable seasonal changes were also to be taken care of during the culture period at Pizhala.

Transport mechanism of the instantaneous release of particles emulating the waste material from the fish cage: Particle tracking module coupled with FVCOM 3D were used to study the effect of hydrographic conditions on the transport of waste materials at Pizhala cage farms. Two distinct simulations over a tidal cycle were conducted during pre-monsoon (Fig. 8) and monsoon periods in 2015 (Fig. 9). Even if the shallow depth $(<5 \mathrm{~m})$ at Pizhala, weak continuous flows $(<0.12 \mathrm{~m} / \mathrm{s})$ were able to transport the waste materials to the downstream regions of the VL within a tidal cycle. The shifting up of the average velocity in monsoon (Fig. 6b) from the pre-monsoon (Fig. 4b) resulted in the quick flushing of the particles through the north-west channel (Fig. 9b) within the $12 \mathrm{hr}$ of the initial

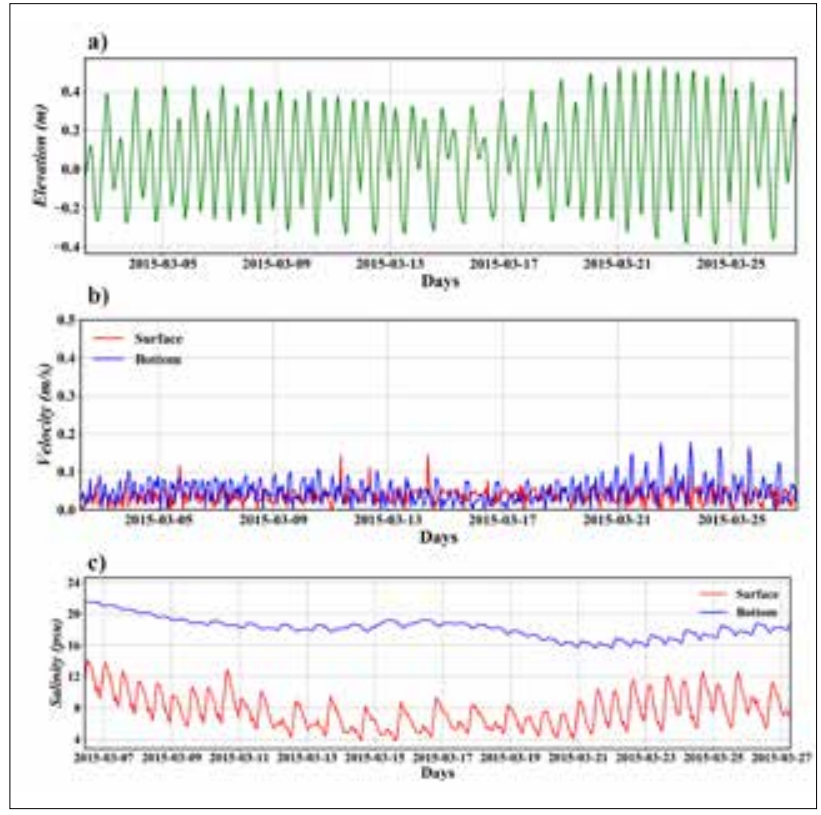

Fig. 4. Simulated hydrodynamic conditions (a-water level, b-velocity, c- salinity) of Pizhala during pre-monsoon period. 


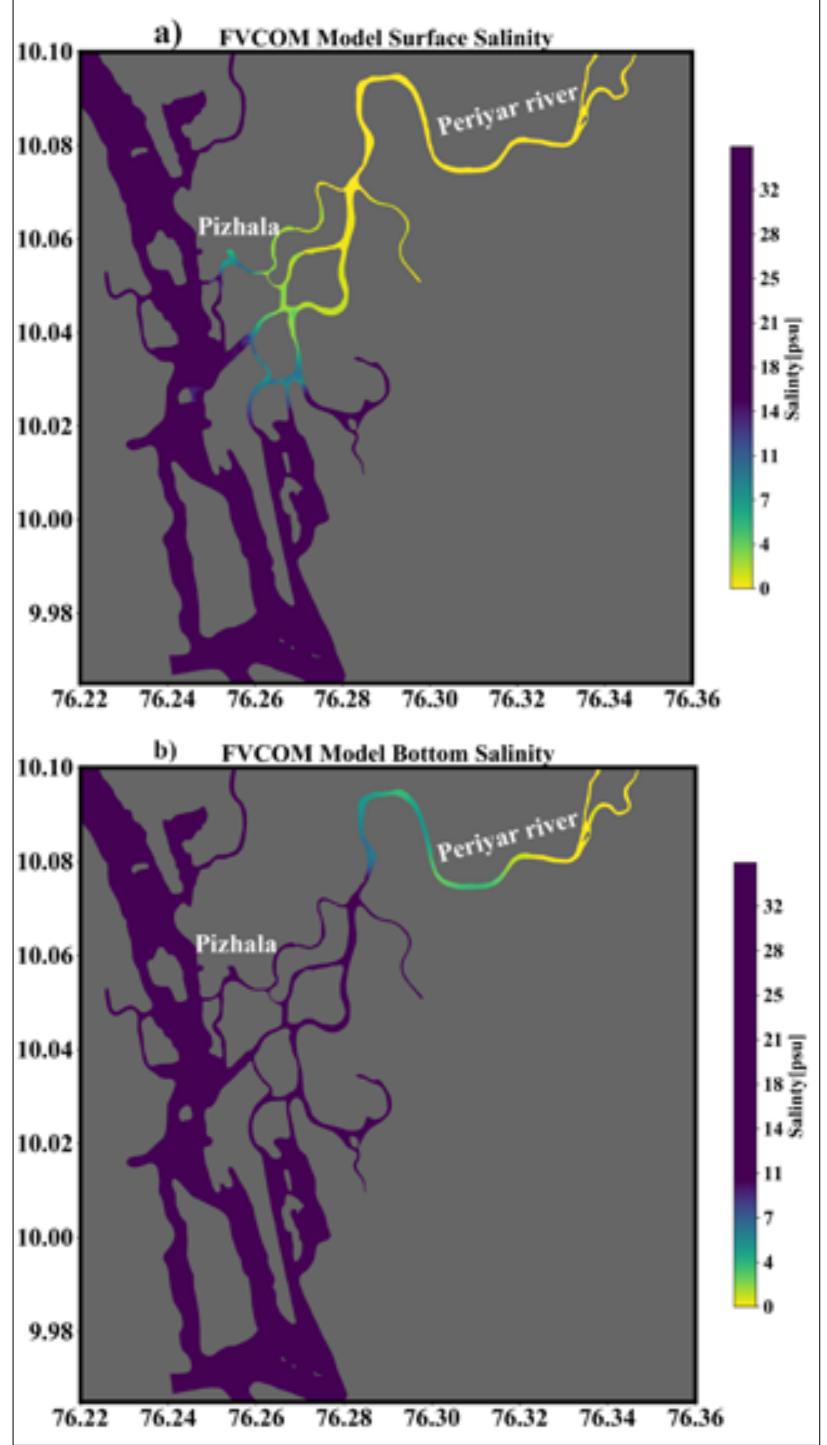

Fig. 5. Simulated surface and bottom salinity of the VL during the premonsoon (spring).

release. In pre-monsoon, the complete flushing was took place through the north-east channel within the 24-hr (Fig. $8 b)$. This may relatively reduce the supply of new oxygenated water to the cage than in the monsoon. The particles resided in the surrounding regions of the cages for a longer time were promoted to the deposition of waste material on the sea bed. However, the particle with larger settling velocities may be led to enhance the deposition under the fish farm irrespective of the flow patterns. In contrast, the particles with small settling velocities can experience a widespread of transport with respect to the flow, and it diminishes the average deposition rates beneath of the cage.

Analysis of seasonal sediment characteristics confirms the simulation of the hydrodynamics and particle movements

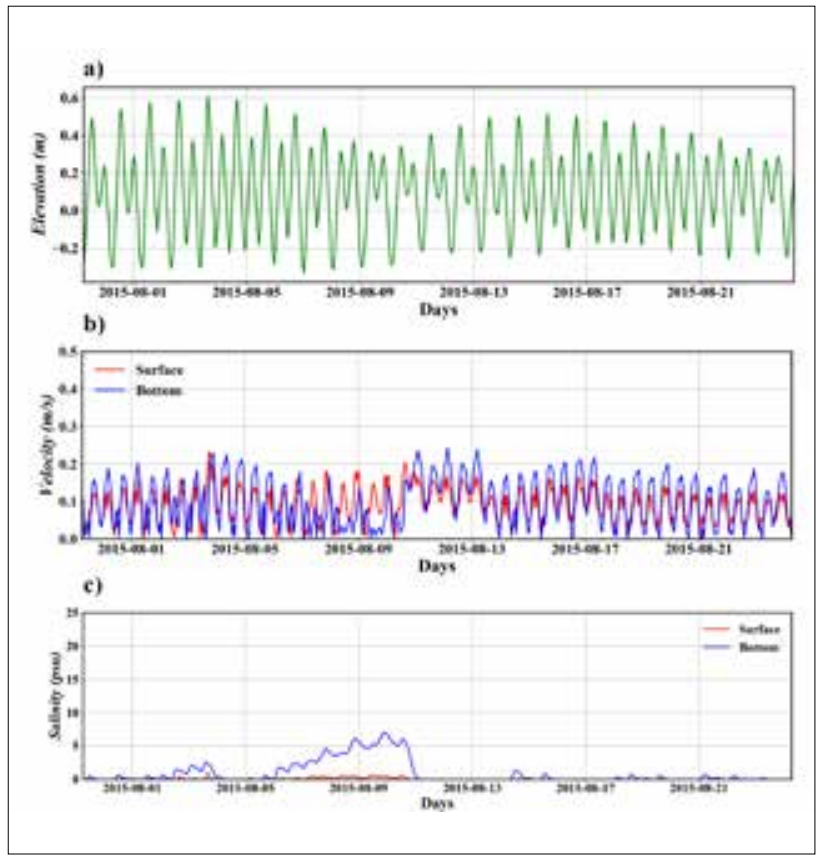

Fig. 6. Simulated hydrodynamic conditions (a-water level, b-velocity, c- salinity) of Pizhala during the monsoon period.

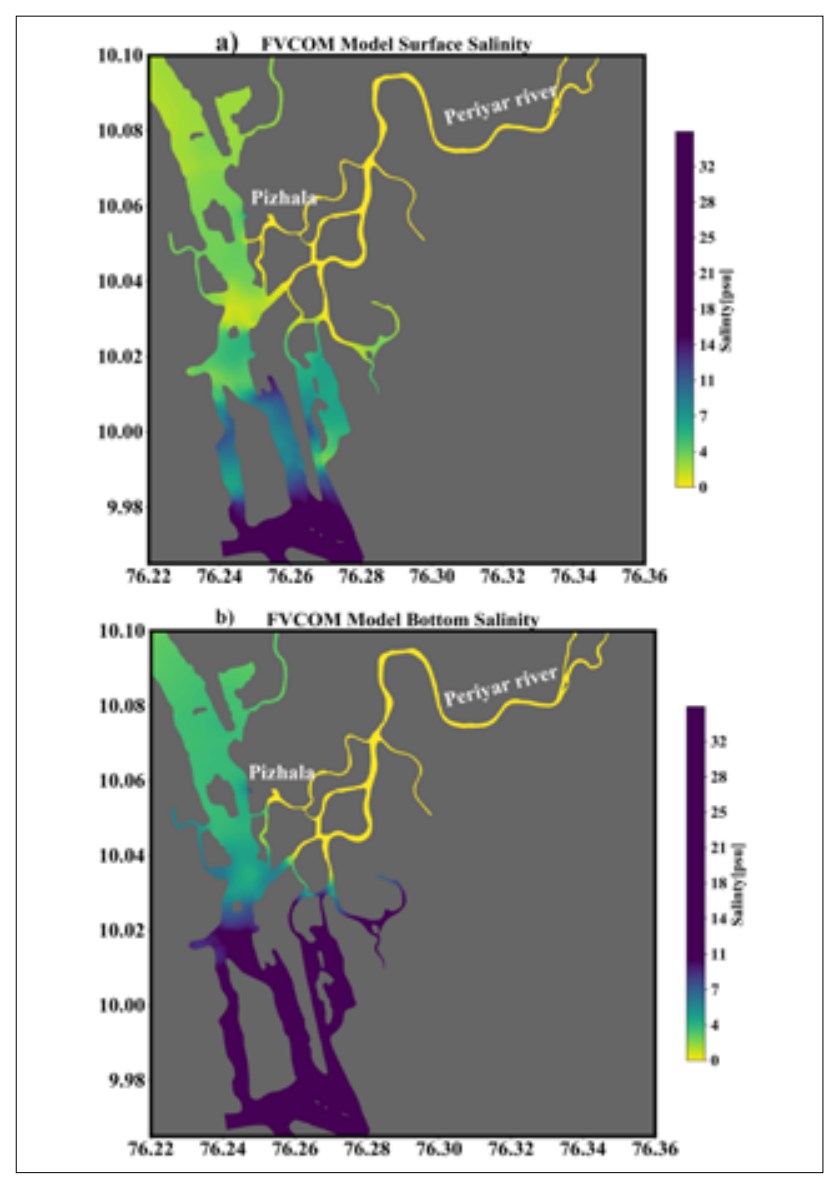

Fig. 7. Simulated surface and bottom salinity of the VL during the monsoon (spring). 
at Pizhala. Sediment surrounding the cage farming site has been observed to be enriched with organic carbon than the reference station in pre-monsoon and monsoon (Table. 6). However, the highest values of organic carbon in sediments around the farming site were associated with lower velocity $(<0.12 \mathrm{~m} / \mathrm{s})$ and higher residence time $(\sim 24 \mathrm{hr})$ in premonsoon rather than the monsoon. Sediment texture also showed conspicuous variation among seasons, and the clay particles were predominant in the cage framing site than the reference station in both seasons. The organic carbon content was found to be less in the sediment with higher percentage of coarse particles. This is due to lesser surface area for holding organic matter in coarser particle (Nayar et al., 2007; Rehitha et al., 2019) . Increase in organic carbon in pre-monsoon can change the physical and chemical properties of sediment (Hall et al., 1992; 1990; Holby and Hall, 1991; Hargrave et al., 1993; Karakassis et al., 2000, 1998). This in turn will affect the benthic community structure and modifies the ecosystem functioning by reducing the oxygen content in the sediment (Tomassetti et al., 2016). Most studies indicate that a spatial gradient of waste disposal and a degraded natural environment are within 100 $\mathrm{m}$ of the cages and this was observed in the present analysis too (Holmer, 1992; Pearson and Black, 2000). Rapid flushing characteristics of the monsoon season will further promote the washing of sediment loads, thus creating a healthy environment in the cage and sustenance with higher yields.
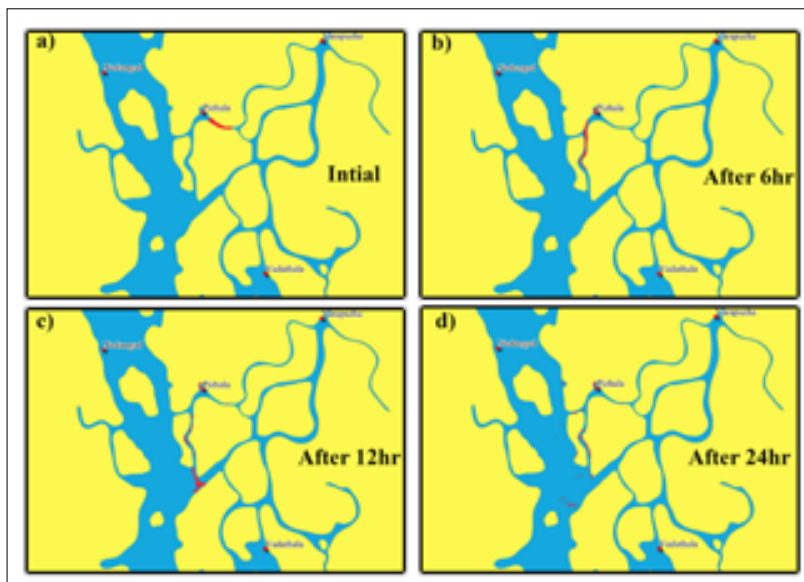

Fig. 8. Simulation of instantaneous 1000 particles (red colored) emulating the waste discharges at cage farm over a tidal cycle in premonsoon (2015).

Table 6. Seasonal sediment characteristics of farming site and reference site at Pizhala

\begin{tabular}{lllll}
\hline \multirow{2}{*}{ Grain size $(\%$ of total) } & \multicolumn{2}{l}{ Pre-monsoon } & \multicolumn{2}{l}{ Monsoon } \\
\cline { 2 - 5 } & Farming site & Reference site & Farming site in & Reference site \\
\hline Sand $(>0.06 \mathrm{~mm})$ & 1.39 & 49.23 & 56.44 & 75.49 \\
\hline Silt $(0.002-0.06 \mathrm{~mm})$ & 36.26 & 30.71 & 19.64 & 10.65 \\
\hline Clay $(<0.002 \mathrm{~mm})$ & 62.38 & 20.05 & 23.13 & 13.86 \\
\hline Organic carbon $(\mathrm{mg} / \mathrm{g})$ & 41.94 & 20.82 & 13.54 & 7.78 \\
\hline
\end{tabular}
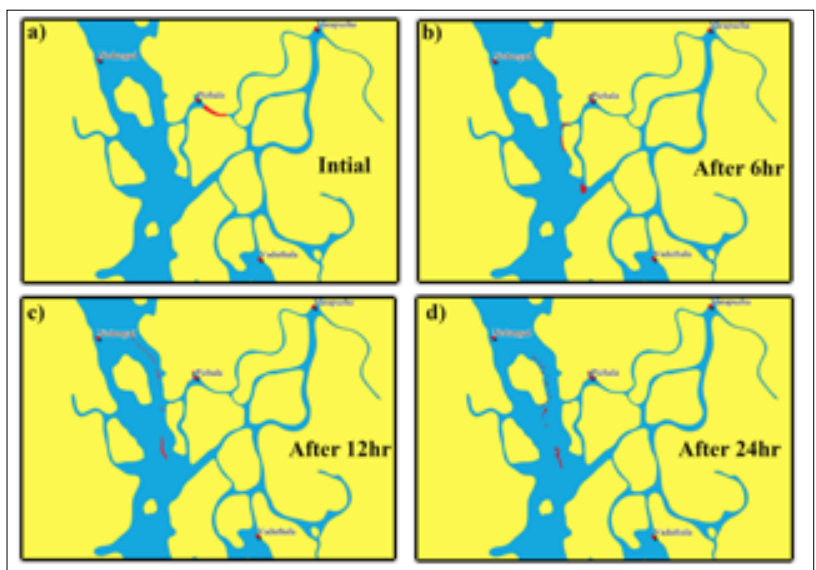

Fig. 9. Simulation of instantaneous 1000 particles (red colored) emulating the waste discharges at cage farm over a tidal cycle in monsoon (2015).

Our study highlighted that the different levels of hydrodynamic conditions promoted waste dispersal of fish farms surrounded the cages. The widespread acceptance of the cages in Pizhala has already been reported, which also confirmed in satellite images by increased number of cages from 2015-2017 (Fig. 2). The prevailing dynamics at Pizhala is conducive for the removal of waste materials produced from the cages and bringing of the oxygenated water to the cages. This was one of the reason to scripting success stories of the cage culture at Pizhala. However, the regulatory measurements are highly essential to understand the carrying capacity in this region for further installation of cages.

We used FVCOM 3D model to assess the water exchange capacity at the cage fish farm at Pizhala and ascertained its suitability as a potential site for cage farming. Strong tidal variability in the water level experienced with an average range of $0.7 \mathrm{~m}$ with a speed of $<0.12 \mathrm{~m} / \mathrm{s}$ in pre-monsoon and $<0.24 \mathrm{~m} / \mathrm{s}$ in monsoon. This consistent flow patterns in the Pizhala region helps to the replenishment of oxygenated water and removal of waste produced at beneath of cages. This is further substantiated with the Lagrangian transport model experiment coupled with FVCOM. Waste materials generated from uneaten food and fish faeces with small settling velocities are able to transport away by the prevailing currents, thus reducing the chances of deposition at the cage bed. VL-FVCOM model, in conjunction with a particle tracking model, can be used as an effective tool for selecting a suitable location for cage culture in VL. GIS can further refine the hydrodynamic model results for planning, regulation, and monitoring and site selection for cage aquaculture.

\section{Acknowledgements}

The authors thank Director, NIO, Goa, and Scientist-in-Charge, $\mathrm{NIO}$, Cochin, for the encouragement and support. We are grateful 
to A. C. Anil, Project Leader, OCEAN FINDER (PSC 0105) for financial support. We acknowledge ICMAM, Chennai (Ministry of Earth Sciences, India), Naval Research Board (NRB) and CSIRNIO (Council of Scientific \& Industrial Research, India) for the financial support to carry out this study. We want to thank the FVCOM development team members in the Marine Ecosystem Dynamics and Modelling Laboratory, School of Marine Science and Technology, UMASSD for providing FVCOM source code. Also, we wish to thank the Director, ICAR-CMFRI Kochi and CSIR-UGC for providing financial support for conducting the survey at Pizhala.

\section{References}

Assefa, W. W., W. B. Abebe, A. P. Estigade, A. P. Astuti, A. Wicaksono, T. Maitela and W. Widyatmanti. 2018. Remote sensing and GIS application for water environment suitability evaluation in Lampung and Hurun Bay, in: IOP Conference Series: Earth and Environmental Science. Springer, $72 \mathrm{pp}$.

Aswathy, N. and J . Imelda. 2018. Economic viability of cage farming of Asian seabass in the coastal waters of Kerala. Int. J. Fish. Aquat. Stud., 6: 368-371.

Chen, C., H. Liu and R. C.Beardsley. 2003. An unstructured grid, finite-volume, threedimensional, primitive equations ocean model: Application to coastal ocean and estuaries. J. Atmos. Ocean. Technol., 20:159-186.

Cromey, C. J. and K. D. Black. 2005. Modelling the impacts of finfish aquaculture, in: Environmental Effects of Marine Finfish Aquaculture. Springer, p. 129-155.

Cromey, C. J., T. D. Nickell and K. D. Black. 2002. DEPOMOD-modelling the deposition and biological effects of waste solids from marine cage farms. Aquaculture, 214: 211-239.

Department of Animal Husbandry Dairying \& Fisheries, 2018. Guidlines for sea cage farming in india. Ministry of Agriculture \& Farmers welfare,Government of India

Edgar, G. J., A. Davey and C. Shepherd. 2010. Application of biotic and abiotic indicators for detecting benthic impacts of marine salmonid farming among coastal regions of Tasmania. Aquaculture, 307:212-218.

El Wakeel, S. K. and J. P. Riley. 1957. The determination of organic carbon in marine muds. ICES J. Mar. Sci., 22:180-183.

Estigade, A. P., A. P. Astuti, A. Wicaksono, T. Maitela and W. Widyatmanti, 2019. Remote sensing and GIS application for water environment suitability evaluation in Lampung and Hurun Bay, in: IOP Conference Series: Earth and Environmental Science, $12016 \mathrm{pp}$.

Falconer, L., D. C. Hunter, T. C. Telfer and L. G. Ross. 2013. Visual, seascape and landscape analysis to support coastal aquaculture site selection. Land use policy 34:1-10.

Findlay, R. H. and L. Watling. 1994. Toward a process level model to predict the effects of salmon net-pen aquaculture on the benthos p 47-77. Chapter 4. Can. Tech. Rep. Fish. Aquat. Sci. 1949

Gowen, R. J., N. B. Bradbury and J. R. Brown. 1989. The use of simple models in assessing two of the interactions between fish farming and the marine environment. In: De Pauw, N. et al. (Ed.) Aquac. Biotechnol. Prog., 2: 10711080.

Hall, P. O. J., L. G. Anderson, O. Holby, S. Kollberg and M. O. Samuelsson. 1990. Chemical fluxes and mass balances in a marine fish cage farm. I. Carbon. Mar. Ecol. Prog. Ser., 61: 61-73.

Hall, P. O. J., O. Holby, S. Kollberg and M. O. Samuelsson.1992. Chemical fluxes and mass balances in a marine fish cage farm. IV. Nitrogen. Mar. Ecol. Prog. Ser., 89: $81-91$

Hargrave, B. T., D. E. Duplisea, E. Pfeiffer and D. J. Wildish. 1993. Seasonal changes in benthic fluxes of dissolved oxygen and ammonium associated with marine cultured Atlantic salmon. Mar. Ecol. Prog. Ser., 96: 249-257.

Hevia, M., H. Rosenthal and R. J. Gowen. 1996. Modelling benthic deposition under fish cages. J. Appl. Ichthyol., 12:71-74.

Holby, O. and P. O. J. Hall.1991. Chemical fluxes and mass balances in a marine fish cage farm. II. Phosphorus. Mar. Ecol. Prog. Ser., p. 263-272.
Holmer, M. 2010. Environmental issues of fish farming in offshore waters: perspectives, concerns and research needs. Aquac. Environ. Interact., 1:57-70.

Holmer, M. 1992. Impacts of aquaculture on surrounding sediments: generation of organic-rich sediments. EAS Spec. Publ., 16: 155-75.

Imelda, J. and A. Gopalakrishnan. 2017. Cage Farming Headed For Equal Opportunity In Aquaculture Development In Kerala, India. Asian Fisheries Science Special Issue $30 S$ (2017): 387-391

John, S., K. R. Muraleedharan, C. Revichandran, S. A. Azeez, G. Seena and P. W. Cazenave. 2020. What Controls the Flushing Efficiency and Particle Transport Pathways in a Tropical Estuary? Cochin Estuary, Southwest Coast of India. Water, 12 (3): 908.

Karakassis, I., M. Tsapakis and E. Hatziyanni. 1998. Seasonal variability in sediment profiles beneath fish farm cages in the Mediterranean. Mar. Ecol. Prog. Ser., 162: 243-252.

Karakassis, I., M. Tsapakis, E. Hatziyanni, K. N. Papadopoulou and W. Plaiti. 2000 Impact of cage farming of fish on the seabed in three Mediterranean coastal areas. ICES J. Mar. Sci., 57: 1462-1471.

Krumbein, W. C. and F. J. Pettijohn. 1938. Manual of sedimentary petrography D. Appleton-Century, $549 \mathrm{pp}$

Machias, A., I. Karakassis, M. Labropoulou, S. Somarakis, K. N. Papadopoulou and C. Papaconstantinou. 2004. Changes in wild fish assemblages after the establishment of a fish farming zone in an oligotrophic marine ecosystem. Estuar. Coast. Shelf. Sci. 60:771-779.

Menon, N. N., A. N. Balchand and N. R. Menon. 2000. Hydrobiology of the Cochin backwater system-a review. Hydrobiologia, 430: 149-183.

Nayar, S., D. J. Miller, A. Hunt, B. P. L. Goh and L. M. Chou. 2007. Environmental effects of dredging on sediment nutrients, carbon and granulometry in a tropical estuary. Environ. Monit. Assess. 127: 1-13.

Pearson, T. H. and K. D. Black, 2000. The environmental impacts of marine fish cage culture. Environ. impacts Aquac., p 1-31.

Pérez, O. M., T. C. Telfer, M. C. M. Beveridge and L. G. Ross. 2002. Geographical Information Systems (GIS) as a simple tool to aid modelling of particulate waste distribution at marine fish cage sites. Estuar. Coast. Shelf. Sci., 54:761-768.

Rehitha, T. V., N. V. Madhu, G. Vineetha, P. V. Vipindas, P. Resmi and C. Revichandran. 2019. Spatio-temporal variability in macrobenthic communities and trophic structure of a tropical estuary and its adjacent coastal waters. Environ. Monit. Assess., 191: 341.

Revichandran, C., K. Srinivas, K. R. Muraleedharan, M. Rafeeq, S. Amaravayal, K. Vijayakumar and K. V. Jayalakshmy. 2012. Environmental set-up and tidal propagation in a tropical estuary with dual connection to the sea (SW Coast of India). Environ. Earth Sci., 66:1031-1042.

Riera, R., A. Sacramento, O. Perez, O. Monterroso, E. Ramos, M. Rodriguez and E. Almansa. 2013. Effects of organic enrichment on macrofauna community structure: an experimental approach. Brazilian J. Oceanogr., 61: 223-229.

Ross, L. G., L. L. Falconer, A. Campos Mendoza and C. A. Martinez Palacios. 2011. Spatial modelling for freshwater cage location in the Presa Adolfo Mateos Lopez (El Infiernillo), Michoacán, México. Aquac. Res., 42:797-807.

Ross, L. G., T. C. Telfer, L. Falconer, D. Soto and J. Aguilar-Majarrez. 2013. Site selection and carrying capacities for inland and coastal aquaculture. FAO.

Srinivas, K., C. Revichandran, P. A. Maheswaran, T. T. M. Asharaf and N. Murukesh.2003. Propagation of tides in the Cochin estuarine system, southwest coast of India. Indian J. Geo-Marine Sci., 32:14-24.

Stigebrandt, A., J. Aure, A. Ervik and P. K. Hansen. 2004. Regulating the local environmental impact of intensive marine fish farming: III. A model for estimation of the holding capacity in the Modelling-Ongrowing fish farm-Monitoring system. Aquaculture, 234:239-261.

Tomassetti, P., P. Gennaro, L. Lattanzi, I. Mercatali, E. Persia, D. Vani and S. Porrello. 2016. Benthic community response to sediment organic enrichment by Mediterranean fish farms: Case studies. Aquaculture, 450:262-272.

Vinita, J., A. Shivaprasad, N. T. Manoj and C. Revichandran. 2015. Spatial tidal asymmetry of Cochin estuary, West Coast, India, p. 537-551.

Willmott, C. J. 1981. On the validation of models. Phys. Geogr., 2:184-194.

Winsby, M., B. Sander, D. Archibald, M. Daykin, P. Nix, F. J. R. Taylor and D. Mundy. 1996. The environmental effects of salmon net-cage culture in British Colombia. Victoria Minsitry of Environment, Lands and Parks, Environmental Protection Dept. Industrial Waste/Hazardous Contaminants Branch. 